\title{
Knowledge, attitudes, and practices toward Covid-19 among the Mongolian general population during the period of the Covid-19 pandemic: a nationwide, population-based, randomised, cross-sectional study
}

Enkhnaran Tumurbaatar ${ }^{1,2}$, Enkhjin Bat-Erdene ${ }^{1}$, Otgontuya Duurenjargal ${ }^{3}$, Myagmartseren Erbat ${ }^{3}$, Tsolmontuya Amartuvshin ${ }^{4}$, Myagmartseren Dashtseren ${ }^{4}$, Gantsetseg Tumur-Ochir ${ }^{3}$, Damdindorj Boldbaatar ${ }^{5}$, Oka Takakazu ${ }^{6}$, Battuvshin Lkhagvasuren ${ }^{1,6}$, Tsolmon Jadamba ${ }^{7,8, *}$

${ }^{1}$ Brain Science Institute, Graduate School, Mongolian National University of Medical Sciences, Ulaanbaatar, Mongolia

${ }^{2}$ Department of International Cyber Education, Graduate School, Mongolian National University of Medical Sciences, Ulaanbaatar, Mongolia.

${ }^{3}$ Department of Mental Health, School of Medicine, Mongolian National University of Medical Sciences, Ulaanbaatar, Mongolia

${ }^{4}$ Department of Family Medicine, School of Medicine, Mongolian National University of Medical Sciences, Ulaanbaatar, Mongolia

${ }^{5}$ Mongolian National University of Medical Sciences, Ulaanbaatar, Mongolia

${ }^{6}$ Department of Psychosomatic Medicine, International University of Health and Welfare Narita Hospital, Narita, Chiba, Japan

${ }^{7}$ Timeline Research Center, Ulaanbaatar, Mongolia

${ }^{8}$ Center of Excellence in Brain Research, Institute of Biology, Mongolian Academy of Sciences, Ulaanbaatar, Mongolia

* Correspondence: tsolmon@mas.ac.mn; Tel.: +976-99117627

Received: 5 July 2021; Accepted: 23 September 2021; Published: 1 December 2021

Edited by: Norshariza Nordin (Universiti Putra Malaysia, Malaysia)

Reviewed by: Maralgua Och (Mongolian National University of Medical Sciences, Mongolia);

Adib Valibeygi (Fasa University of Medical Sciences, Fasa, Iran)

https://doi.org/10.31117/neuroscirn.v4i3Suppl.102

Abstract: Improving knowledge, attitudes, and practices toward COVID-19 is critical to control the infection rate of the pandemic successfully. Mongolia declared a state of emergency in January 2020 but no study was performed on public adherence to centralised measures and awareness of the pandemic in Mongolia. This study aimed to determine knowledge, attitudes, and practices (KAP) toward COVID-19 in the general population, especially regarding the extent to which KAP has contributed to the control measures before local COVID-19 outbreaks. The study was conducted between July and October 2020, when the pandemic was limited to internationally imported cases. We adapted a structured KAP questionnaire that was used to survey residents of Wuhan, China, during the initial outbreak of the pandemic. Participants aged between 13 and 65 years ( $n=1324$, mean age $=39.79 \pm 14.8$ ), $73.2 \%$ were women, and $27.2 \%$ held a bachelor's degree or above. The results suggested that $81.9 \%$ of the participants had sufficient knowledge about the transmission, symptoms, treatment, and prevention of the disease. In the multiple linear regression, an increase in age and education contributed positively to a high knowledge score $(p<0.05, p<0.001$, respectively). The majority of the participants $(96.2 \%-96.5 \%)$ had compliance with the measures to control COVID-19 spread with good practices (82.4\% - 93.1\%) toward COVID-19 prevention. In the binary logistic regression analyses, the COVID19 knowledge score was associated with a higher likelihood of optimistic attitudes and preventive practices (OR: $0.617-0.845$ ). In conclusion, despite the sufficient knowledge toward the COVID-19 pandemic among the general population of Mongolia, a relatively low level of optimistic attitudes and appropriate practices 
compared to other populations may negatively impact preventing the outbreak in the society. Health education programs aimed at improving COVID-19 knowledge will be helpful to minimise local epidemic growth and the current government measures such as lockdowns, quarantines, and travel restrictions.

Keywords: COVID-19; KAP; nationwide population-based; cross-sectional; Mongolia;

C2021 by Tumurbaatar et al. for use and distribution according to the Creative Commons Attribution (CC BY-NC 4.0) license (https://creativecommons.org/licenses/by-nc/4.0/), which permits unrestricted non-commercial use, distribution, and reproduction in any medium, provided the original author and source are credited.

\subsection{INTRODUCTION}

COVID-19, also known as the coronavirus pandemic, is caused by severe acute respiratory syndrome coronavirus 2 (SARS-CoV-2) and was first detected in December 2019 in Wuhan, China. This highly contagious pandemic is ongoing, with an overall infection fatality rate of $0.6-1.1 \%$ (Ngwewondo et al., 2020). Earlier studies have shown that the overall case fatality rate of COVID-19 is $2.3 \%$ in China, lower than those of SARS (9.5\%), MERS (34.4\%), and H7N9 (39.0\%) (Munster et al., 2020). By October 2020, the COVID- 19 pandemic had spread to 215 countries, while there were only 338 laboratory-confirmed imported cases without local infections and mortality in Mongolia (Ministry of Health Mongolia, 2020), (WHO, 2020a). In Mongolia, the Government declared a state of emergency in January 2020 with an array of measures to curb the infections, much earlier than the WHO's decision to announce a pandemic in March 2020 (WHO, 2020b). Those centralised measures included personal safety protection, curfew, international travel restrictions, quarantines of international travellers, closures of educational institutions accompanied by infection surveillance that lasted until September 2020 (Erkhembayar et al., 2020). These public health measures delayed the first confirmed infection case until March and prevented the first local infection outbreak in society until November 2020.

People's adherence to these control measures is essential, primarily affected by their knowledge, attitudes, and practices (KAP) toward COVID-19 (Tachfouti et al., 2012). Previous studies suggest that public awareness of the epidemic nature and adherence to the control measures play an important role in preventing the spread of the pandemic (Bener \& AlKhal, 2004). So far, there has been no KAP study on COVID-19 in Mongolia, which determines public awareness concerning a range of knowledge about the causes, infection routes, symptoms, complications, treatment modalities, and prognosis of the disease. Low awareness may result in a potential risk of an infection outbreak. Since November, it has been reported by the Ministry of Health that there are 1692 confirmed cases and 2 deaths as of January $28^{\text {th }}, 2021$.

To facilitate outbreak management of COVID-19 in Mongolia, there is an urgent need to understand the public's awareness of COVID-19 at this critical moment. In this study, we aimed to investigate KAP toward COVID-19 among the Mongolian population during the controlled period of the COVID-19 pandemic.

\subsection{MATERIALS AND METHODS}

Brain Science Institute at the Mongolian National University conducts a nationwide multicentred, interdisciplinary, prospective, population-based cohort study to investigate brain-related disorders in the general population of Mongolia (MonTimeLine). The current population of Mongolia is 3,305,576 based on the latest United Nations data, of which half of them live in Ulaanbaatar, the capital city, and the remaining half of them live in 4 rural regions. The cohort consists of 64 sampling centres, including 30 primary health centres of 8 districts in Ulaanbaatar and 34 primary health centres of 4 rural regions in Mongolia. Primary health centres provide health care services to all individuals within certain geopolitical units where the entire population is registered by name, age, gender, education, employment, and household income (Figure 1). 


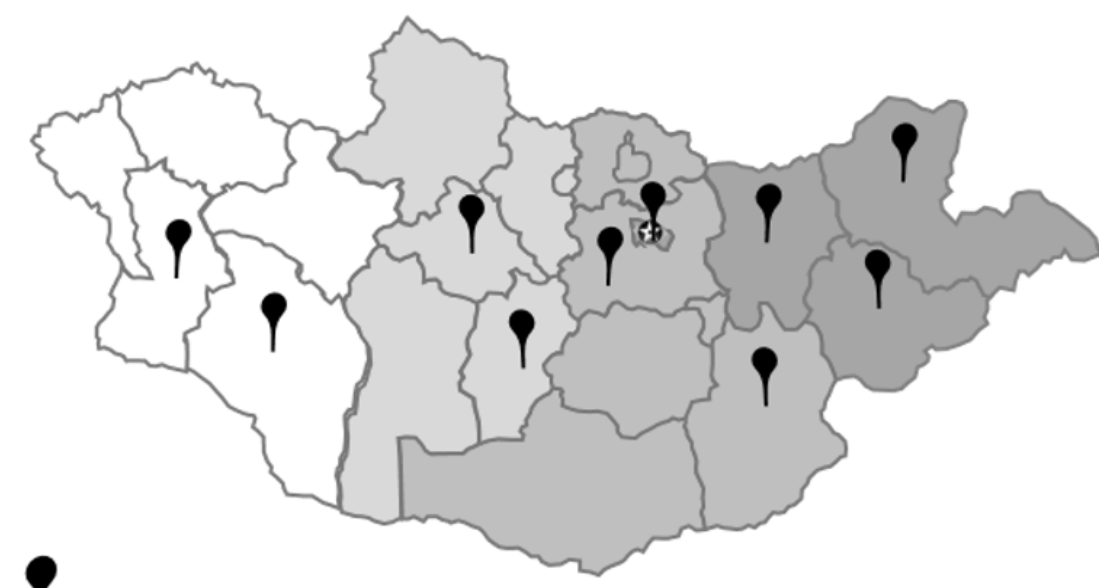

Sampling clusters

Western region: 6 centers in 2 geopolitical prefectures

Mountain region: 6 centers in 2 geopolitical prefectures

Central region: 7 centers in 3 geopolitical prefectures

Eastern region: 7 centers in 3 geopolitical prefectures

\&laanbaatar city: 38 centers in 8 districts

Figure 1: MonTimeLine Cohort centres across Mongolia. The cohort consists of 64 sampling centres, including 38 primary health centres of 8 districts in Ulaanbaatar and 26 primary health centres of 4 rural regions in Mongolia.

In this cross-sectional study, we randomly selected 40 individuals aged 13 or older from each centre. Only Mongolian citizens who lived in the units for at least 6 months were considered to meet inclusion criteria. If selected participants were not available at the centre for the paper-based study, they were replaced by the following available participants regardless of age and sex category.

A total of 1,976 participants were approached to complete the survey. Five hundred seventeen of those approached either did not complete or refused to take the KAP survey. One hundred thirty-five participants were excluded due to missing dependent variables in the KAP survey. One thousand three hundred twentyfour participants were included in the final analysis. The survey started on the 24 July and the preliminary dataset was extracted on the 18 October 2020. The KAP survey was administered in the official language, Mongolian.

We adapted a structured KAP questionnaire to survey residents of Wuhan, China, during the initial outbreak of the pandemic. The questionnaire was translated into Mongolian then translated back to English by two independent reviewers, followed by an expert committee review. Demographic variables included age, gender, marital status, education level, occupation, income, and place of current residency. Briefly, the questionnaire was divided into three subsections and contained a total of 16 questions. There are 12 questions on the knowledge about COVID-19, 2 questions on the adherence of centralised measures, and 2 questions on the regular practice to prevent the infection. These questions have three answers with a true/false basis and an additional "I don't know" option. A correct answer was assigned 1 point, whereas incorrect and "I do not know" answers were assigned 0 points. The total knowledge score ranged from 0 to 12 , with a higher score referring to a better knowledge of COVID-19. The overall Cronbach's alpha coefficient of the knowledge questions was 0.65, indicating an acceptable internal consistency (Table 1) (Taber, 2018).

Data were analysed using SPSS for Windows, v26. Data were not normally distributed by the KolmogorovSmirnov test (df: 1324, statistic: 0.321, $\mathrm{P}<0.001$ ). Differences in knowledge scores between demographic variables were tested using the independent samples Mann-Whitney $U$ test or one-way analysis of variance (Woods et al. 2020) as appropriate. Differences in attitudes and practices between demographic variables were tested by the Mann-Whitney U test or the KruskalWallis $\mathrm{H}$ test as appropriate. To identify the causal 
relationship of demographic variables with overall knowledge score, we used the multivariate linear regression, whereas with attitudes or practices, the binary logistic regression or the multinomial logistic regression analyses as appropriate. Factors were selected with a stepwise forward method. Statistical significance was set at $\mathrm{P}<0.05$, and all tests were twotailed. Data were presented as means \pm standard deviations (SD) with $95 \%$ confidence intervals $(\mathrm{CI})$.

\section{Ethical considerations}

Our study was conducted in accordance with the ethical standards outlined in the 1964 World Medical Association Declaration of Helsinki. The institutional review board and Ethics committee of the Mongolian National University of Medical Sciences approved the study protocol and procedures for informed consent on 12 June 2020 (Ethics Nr. 20/03-05).

\subsection{RESULTS}

A total of 1,324 participants completed the survey questionnaire. The average age was 39.79 years (SD: 14.8, range: 16-65), 969 (73.2\%) were women, 359 (27.2\%) held a bachelor's degree or above, 876 (66.2\%) married in a national registering agency and 605 (45.7\%) were residents of Ulaanbaatar city. Other demographic characteristics are shown in (Table 2).

Table 1: Questionnaire of knowledge, attitudes, and practices toward COVID-19.

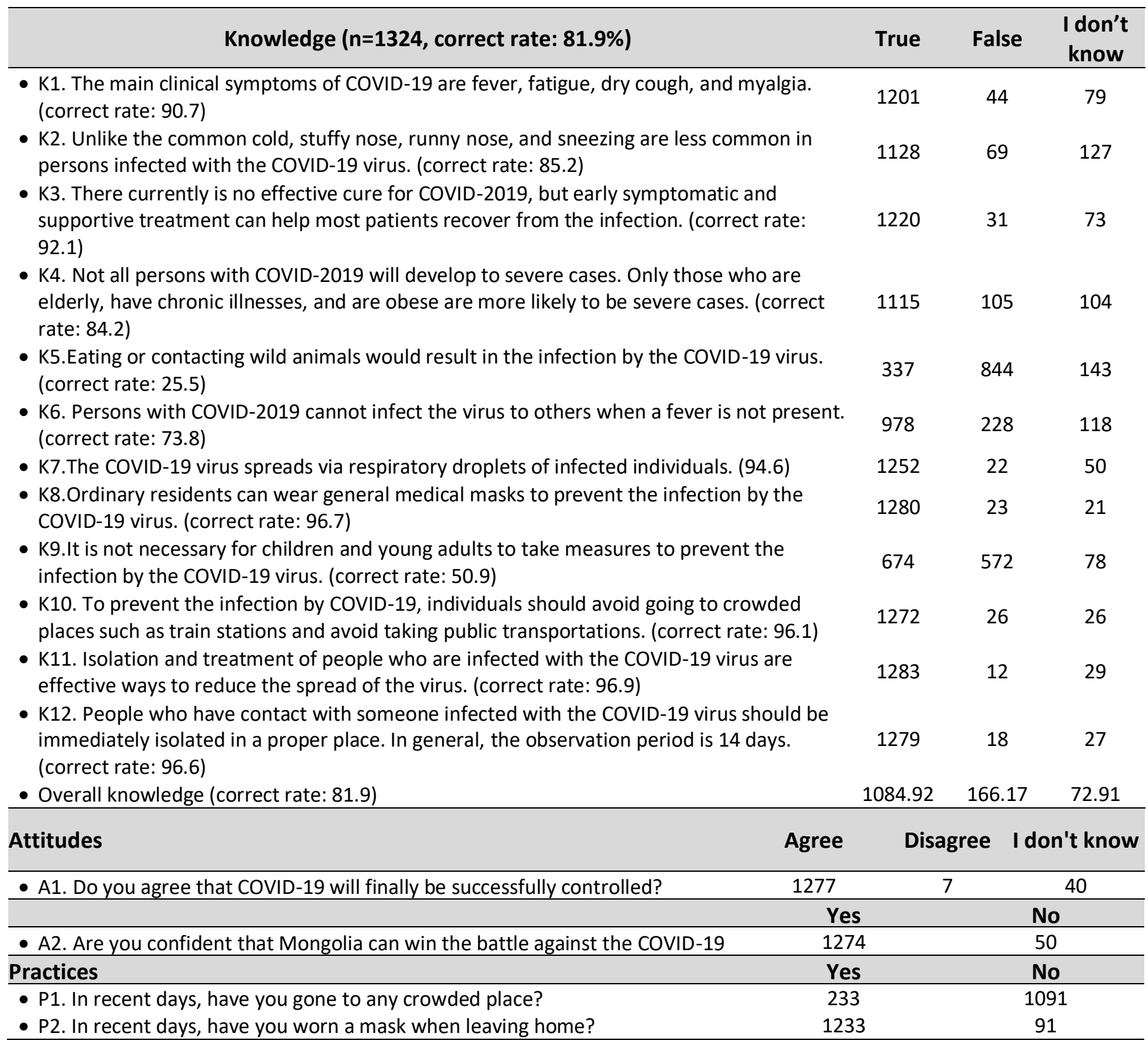


Table 2: Demographic characteristics and knowledge score.

\begin{tabular}{|c|c|c|c|c|c|}
\hline \multicolumn{2}{|c|}{ Characteristics $(n=1324)$} & n (\%) & $\begin{array}{l}\text { Knowledge score } \\
\text { (mean } \pm \text { SD) }\end{array}$ & $\mathbf{T}(\mathbf{d f}) / \mathbf{F}$ & P-value* \\
\hline Gender & $\begin{array}{c}\text { Male } \\
\text { Female }\end{array}$ & $\begin{array}{l}355(26.8) \\
969(73.2)\end{array}$ & $\begin{array}{c}9.1 \pm 1.49 \\
9.22 \pm 1.46\end{array}$ & $-1.35 / 1322$ & 0.108 \\
\hline $\begin{array}{l}\text { Age groups } \\
\text { (years) }\end{array}$ & $\begin{array}{c}13-19 \\
20-29 \\
30-39 \\
40-49 \\
50-59 \\
60< \\
\end{array}$ & $\begin{array}{c}173(13.1) \\
188(14.2) \\
260(19.6) \\
304(23.0) \\
273(20.6) \\
126(9.5) \\
\end{array}$ & $\begin{array}{l}9.06 \pm 1.43 \\
9.31 \pm 1.68 \\
8.99 \pm 1.66 \\
9.22 \pm 1.53 \\
9.22 \pm 1.21 \\
9.47 \pm 1.04\end{array}$ & $5 / 2.421$ & 0.034 \\
\hline Marital status & $\begin{array}{c}\text { Married } \\
\text { Never-married } \\
\text { Others\# }\end{array}$ & $\begin{array}{l}876(66.2) \\
290(21.9) \\
158(11.9)\end{array}$ & $\begin{array}{l}9.21 \pm 1.46 \\
9.1 \pm 1.49 \\
9.26 \pm 1.52\end{array}$ & $2 / 0.821$ & 0.440 \\
\hline Education & $\begin{array}{l}\text { Middle school or below } \\
\text { Associate's degree } \\
\text { Bachelor's degree or above }\end{array}$ & $\begin{array}{l}640(48.3) \\
325(24.5) \\
359(27.2)\end{array}$ & $\begin{array}{l}9.04 \pm 1.53 \\
9.19 \pm 1.41 \\
9.46 \pm 1.39\end{array}$ & 2/9743 & $<0.001$ \\
\hline Employment & $\begin{array}{l}\text { Student } \\
\text { Pensioner } \\
\text { Unemployed } \\
\text { Employed }\end{array}$ & $\begin{array}{l}174(13.1) \\
283(21.4) \\
164(12.4) \\
703(53.1)\end{array}$ & $\begin{array}{l}9.01 \pm 1.32 \\
9.27 \pm 1.02 \\
8.94 \pm 1.25 \\
9.25 \pm 1.57 \\
\end{array}$ & $3 / 2.862$ & 0.036 \\
\hline $\begin{array}{l}\text { Current } \\
\text { residency }\end{array}$ & $\begin{array}{c}\text { Ulaanbaatar } \\
\text { Other parts of Mongolia }\end{array}$ & $\begin{array}{l}605(45.7) \\
719(54.3)\end{array}$ & $\begin{array}{l}9.22 \pm 1.93 \\
9.17 \pm 0.93\end{array}$ & $0.61 / 840.35$ & $<0.001$ \\
\hline Income & $\begin{array}{c}<175 \$ \\
175 \$-525 \$ \\
>525 \$\end{array}$ & $\begin{array}{c}841(63.5) \\
462(34.9) \\
21(1.6)\end{array}$ & $\begin{array}{l}9.13 \pm 1.42 \\
9.28 \pm 1.58 \\
9.57 \pm 0.92\end{array}$ & $2 / 2370$ & 0.094 \\
\hline
\end{tabular}

* P-values were calculated using the independent samples Mann-Whitney test or ANOVA as appropriate.

\# "Others" included re-married, cohabiting, separated, divorced, and widowed.

The correct answer rates of the 12 questions on the COVID-19 knowledge questionnaire were between $25.5 \%$ and $96.9 \%$ (Table 1). The mean COVID-19 knowledge score was 9.19 (SD: 1.47, range: 0-12), indicating an $81.9 \%$ correct rate overall. Knowledge scores significantly differed across age groups, education levels, employment, and current residency (Table 2). Multiple linear regression analyses showed that older age and higher education contributed positively to higher knowledge scores $(P=0.034$, $\mathrm{P}<0.001$, respectively) (Table 3 ).
Most of the participants agreed that COVID-19 would be successfully controlled (96.5\%). The rates of reporting "disagree" and "I don't know" were $0.5 \%$ and $3.0 \%$, respectively. The attitude toward the final success in controlling COVID-19 differed across age groups, current residency, and income. In addition, participants reporting "disagree" and "I don't know" had significantly lower knowledge scores than those reporting "agree" $(\mathrm{P}<0.001)$.

Table 3: Results of multiple linear regression on factors associated with COVID-19 knowledge.

\begin{tabular}{ccccccc}
\hline \multirow{2}{*}{ Variables } & Coefficient & \multicolumn{2}{c}{ 95\% Cl } & Standard & t & P-value* \\
\cline { 3 - 4 } (Woods et al.) & Lower & Upper & error & & \\
\hline Gender & 0.077 & -0.104 & 0.258 & 0.092 & 0.831 & 0.406 \\
Age groups & 0.059 & 0.005 & 0.113 & 0.028 & 2.127 & 0.034 \\
Marital status & 0.048 & -0.072 & 0.168 & 0.061 & 0.788 & 0.431 \\
Education & 0.218 & 0.107 & 0.329 & 0.057 & 3.849 & $<0.001$ \\
Employment & -0.038 & -0.124 & 0.048 & 0.044 & -0.862 & 0.389 \\
Current residency & 0.046 & -0.119 & 0.211 & 0.084 & 0.548 & 0.584 \\
Income & 0.079 & -0.106 & 0.264 & 0.094 & 0.837 & 0.403 \\
\hline
\end{tabular}

* P-values were calculated using the multiple linear regression model. OR, odds ratio; $\mathrm{Cl}$, confidence interval. 
Table 4: Attitudes toward COVID-19 by demographic variables.

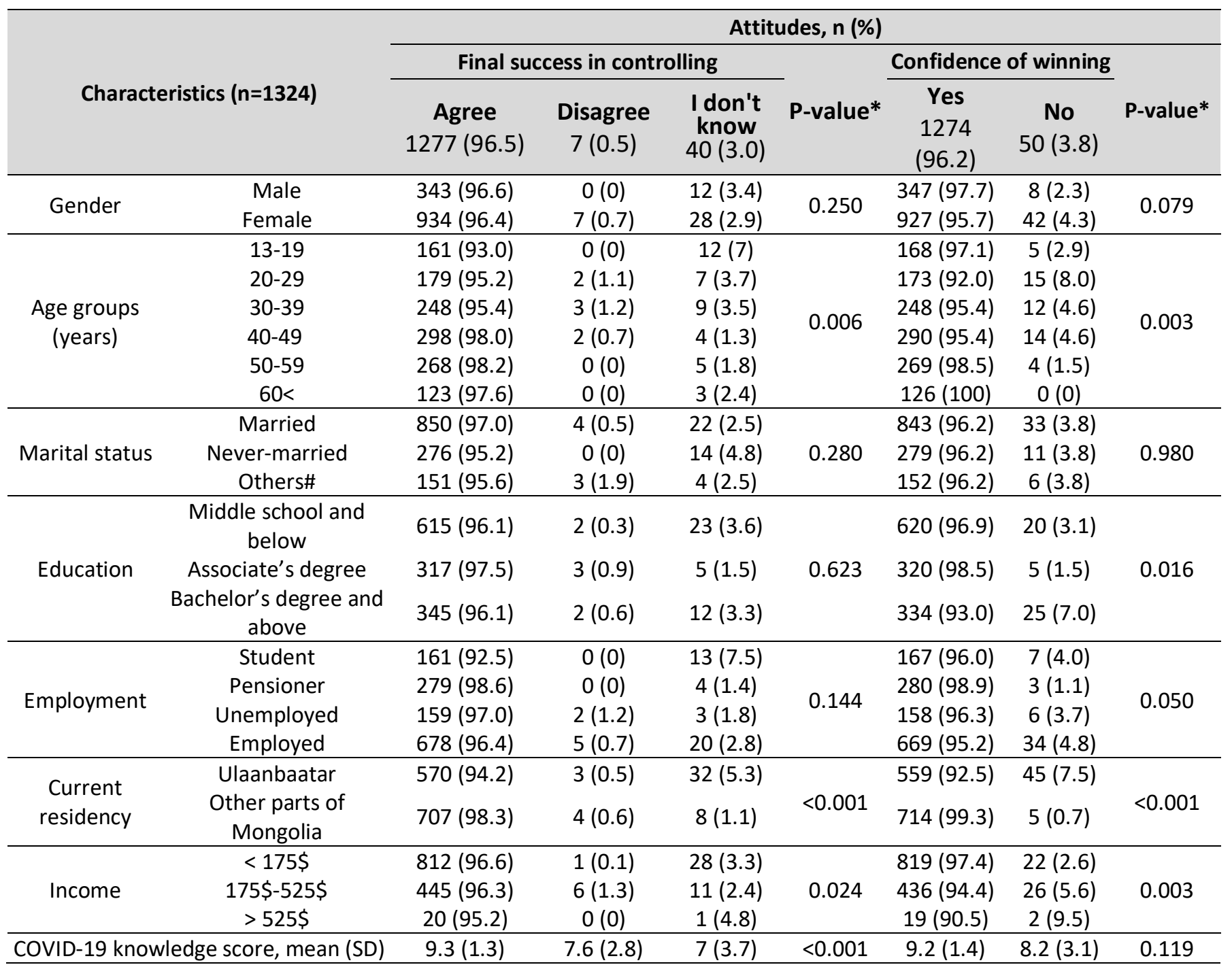

* P-values were calculated using the Mann-Whitney test, Kruskal-Wallis test, or ANOVA as appropriate.

\# "Others" included re-married, cohabiting, separated, divorced, and widowed.

Most participants (96.2\%) believed that Mongolia could win the battle against COVID-19, while $3.8 \%$ had no such confidence. The attitude toward the confidence of winning differed across age groups, education levels, employment, current residency, and income. The COVID-19 knowledge scores were significantly lower in persons without than with confidence of winning $(\mathrm{P}<0.001)$ (Table 4).

Multinomial logistic regression analysis found that the agreement of final success in controlling the pandemic was positively associated with the marital status of "married" compared to "others" ("agree" vs "disagree", OR: 0.157, $P=0.039$ ), and with the current residency of "other parts of Mongolia" compared to "Ulaanbaatar" ("agree" vs "I do not know", OR: 6.05, p<0.001). Binary logistic regression analysis showed that the agreement of confidence in winning the battle against the pandemic was positively associated with the education level of "associated degree" compared to "bachelor's degree or above" (OR: $0.315, \mathrm{P}=0.030$ ), and the current residency of "other parts of Mongolia" compared to "Ulaanbaatar" (OR: 10.33, P<0.001). Similarly, both attitudes were positively associated with higher COVID19 knowledge scores (OR: 0.618, P=0.023; OR: 0.617, $\mathrm{P}<0.001$, respectively) (Table 5).

The majority of the participants had not visited any crowded place $(82.4 \%)$, and at the same time wore masks when going out $(93.1 \%)$ in recent days. The participants who visited a crowded place $(17.6 \%)$ were mostly employed men living in Ulaanbaatar. The participants who did not wear masks when going out 
(6.9\%) were mainly young, never-married, employed people with less income (Table 6).

Binary logistic regression analysis showed that the agreement on the practice of not going to a crowded place was positively associated with a higher education level, employment, and residing out of Ulaanbaatar. In contrast, the agreement on the practice of wearing a mask when going out was positively associated with older age, higher education, and employment (Table 7).

Table 5: Results of multiple binary logistic regression analysis on factors associated with attitudes toward COVID-19.

\begin{tabular}{lcc}
\hline \multicolumn{1}{c}{ Variables } & OR (95\% Cl) & P-value* \\
\hline Final success in controlling the pandemic & & 0.039 \\
\hline Marital status (married vs. others) & $0.157(0.027,0.911)$ & $<0.001$ \\
Current residency (other parts of Mongolia vs. Ulaanbaatar) & $6.053(2.689,13.624)$ & 0.023 \\
COVID-19 knowledge score & $0.618(0.407,0.935)$ & \\
\hline Confidence of winning battle the pandemic & & 0.030 \\
\hline Education (associate's degree vs. bachelor's degree and above) & $0.315(0.112,0.892)$ & $<0.001$ \\
Current residency (other parts of Mongolia vs. Ulaanbaatar) & $10.25(3.963,26.51)$ & $<0.001$ \\
COVID-19 knowledge score & $0.617(0.535,0.712)$ & $<$ \\
\hline
\end{tabular}

* P-values were calculated using the multinomial logistic regression or binary logistic regression as appropriate.

$\mathrm{OR}$, odds ratio; $\mathrm{Cl}$, confidence interval

Table 6: Practices toward COVID-19 by demographic variables.

\begin{tabular}{|c|c|c|c|c|c|c|c|}
\hline \multirow{3}{*}{\multicolumn{2}{|c|}{ Characteristics (n=1324) }} & \multicolumn{6}{|c|}{ Practices, $\mathrm{n}(\%)$ or mean (standard deviation) } \\
\hline & & \multicolumn{3}{|c|}{ Going to a crowded place } & \multicolumn{3}{|c|}{ Wearing a mask when going out } \\
\hline & & Yes & No & D. & Yes & No & inles \\
\hline \multirow{3}{*}{ Gender } & & & & \multirow{3}{*}{0.028} & & & \multirow{3}{*}{0.106} \\
\hline & IVIale & $49(13.8)$ & $300(80.2)$ & & $3<4(91.3)$ & $31(8.1)$ & \\
\hline & Female & $184(19.0)$ & $785(81.0)$ & & $909(93.8)$ & $60(6.2)$ & \\
\hline \multirow{6}{*}{$\begin{array}{l}\text { Age groups } \\
\text { (years) }\end{array}$} & $13-19$ & $32(18.5)$ & $141(81.5)$ & \multirow{6}{*}{0.837} & $151(87.3)$ & $22(12.7)$ & \multirow{6}{*}{$<0.001$} \\
\hline & $20-29$ & $35(18.6)$ & $153(81.4)$ & & $169(89.9)$ & $19(10.1)$ & \\
\hline & $30-39$ & $39(15.0)$ & $221(85.0)$ & & $240(92.3)$ & $20(7.7)$ & \\
\hline & $40-49$ & $62(20.4)$ & $242(79.6)$ & & $291(95.7)$ & $13(4.3)$ & \\
\hline & $50-59$ & $40(14.7)$ & $233(85.3)$ & & $258(94.5)$ & $15(5.5)$ & \\
\hline & $60<$ & $25(19.2)$ & $101(80.2)$ & & $124(98.4)$ & $2(1.6)$ & \\
\hline \multirow{3}{*}{ Marital status } & Married & $143(16.3)$ & $733(83.7)$ & \multirow{3}{*}{0.083} & $830(94.7)$ & $46(5.3)$ & \multirow{3}{*}{0.004} \\
\hline & Never-married & $57(19.7)$ & $233(80.3)$ & & $257(88.6)$ & $33(11.4)$ & \\
\hline & Others\# & $33(20.9)$ & $125(79.1)$ & & $146(92.4)$ & $12(7.6)$ & \\
\hline \multirow{3}{*}{ Education } & Middle school and below & $114(17.8)$ & $526(82.2)$ & \multirow{3}{*}{0.951} & $586(91.6)$ & $54(8.4)$ & \multirow{3}{*}{0.178} \\
\hline & Associate's degree & $53(16.3)$ & $272(83.7)$ & & $314(96.6)$ & $11(3.4)$ & \\
\hline & $\begin{array}{c}\text { Bachelor's degree and } \\
\text { above }\end{array}$ & $66(18.4)$ & $293(81.6)$ & & $333(92.8)$ & $26(7.2)$ & \\
\hline \multirow{4}{*}{ Employment } & Student & $21(12.1)$ & $153(87.9)$ & \multirow{4}{*}{0.011} & $165(94.8)$ & $9(5.2)$ & \multirow{4}{*}{$<0.001$} \\
\hline & Pensioner & $42(14.8)$ & $241(85.2)$ & & 280 (98.9) & $3(1.1)$ & \\
\hline & Unemployed & $32(19.5)$ & $132(80.5)$ & & $158(96.3)$ & $6(3.7)$ & \\
\hline & Employed & $138(19.6)$ & $565(80.4)$ & & $630(89.6)$ & $73(10.4)$ & \\
\hline \multirow{2}{*}{$\begin{array}{l}\text { Current } \\
\text { residency }\end{array}$} & Ulaanbaatar & $177(7.4)$ & $428(92.6)$ & \multirow{2}{*}{$<0.001$} & $561(92.7)$ & $44(7.3)$ & \multirow{2}{*}{0.598} \\
\hline & Other parts of Mongolia & $56(0.7)$ & $663(99.3)$ & & $672(93.5)$ & $47(6.5)$ & \\
\hline \multirow{3}{*}{ Income } & $<175 \$$ & $139(16.5)$ & $702(83.5)$ & \multirow{3}{*}{0.240} & $793(94.3)$ & $48(5.7)$ & \multirow{3}{*}{0.041} \\
\hline & $175 \$-525 \$$ & $93(20.1)$ & 369 (79.9) & & $419(90.7)$ & $43(9.3)$ & \\
\hline & $>525 \$$ & $1(4.8)$ & $20(95.2)$ & & $21(100.0)$ & $0(0)$ & \\
\hline \multicolumn{2}{|c|}{ COVID-19 knowledge score, mean (SD) } & $9.25(1.1)$ & $8.88(2.57)$ & 0.034 & $9.23(1.37)$ & $8.67(2.45)$ & 0.501 \\
\hline
\end{tabular}

* P-values were calculated using the Mann-Whitney test, Kruskal-Wallis test, or ANOVA as appropriate.

\# "Others" included re-married, cohabiting, separated, divorced, and widowed. 
Table 7. Results of multiple binary logistic regression analysis on factors associated with practices toward COVID-19.

\begin{tabular}{lcc}
\hline \multicolumn{1}{c}{ Variables } & OR (95\%Cl) & P-value* \\
\hline Going to a crowded place & & 0.001 \\
\hline Education (bachelor's degree and above vs middle school and below) & $2.058(1.348,3.143)$ & $<0.001$ \\
Employment (employed vs student) & $0.227(0.110,0.466)$ & 0.028 \\
Employment (employed vs pensioner) & $0.564(0.338,0.940)$ & $<0.001$ \\
Current residency (other parts of Mongolia vs. Ulaanbaatar) & $5.774(4.071,8.191)$ & 0.004 \\
COVID-19 knowledge score & $0.882(0.810,0.960)$ & \\
\hline Wearing a mask when going out & & $0.733(0.569,0.945)$ \\
\hline Age groups & $2.349(1.296,4.256)$ & 0.016 \\
Education (bachelor's degree and above vs middle school and below) & $0.075(0.030,0.189)$ & $<0.001$ \\
Employment (employed vs student) & $0.134(0.038,0.471)$ & 0.002 \\
Employment (employed vs pensioner) & $0.259(0.104,0.647)$ & 0.004 \\
Employment (employed vs unemployed) & $0.845(0.754,0.947)$ & 0.004 \\
COVID-19 knowledge score & & \\
\hline
\end{tabular}

* P-values were calculated using the multiple binary logistic regression. $\mathrm{OR}$, odds ratio; $\mathrm{Cl}$, confidence interval

\subsection{DISCUSSION}

This study determined the knowledge, attitude, and practices toward COVID-19 among the Mongolian general population. The results suggest that the participants have sufficient knowledge about the transmission, symptoms, treatment, and prevention of the disease. Mongolians held an optimistic attitude to disease control measures. Most participants complied with the recommended practices such as wearing masks and social distancing to prevent COVID-19 infections.

The first KAP study towards COVID-19 conducted in Hubei province revealed that the correct answer rate of the knowledge questionnaire was excellent, whereas Palestinian and Bangladesh studies showed a marginal correct answer rate (Zhong et al., 2020; Qutob \& Awartani, 2021; Ferdous et al., 2020). Compared to previous studies, our findings demonstrate that the Mongolian general population has moderate knowledge of COVID-19. Our results were similar to the Malaysian KAP study (Azlan et al., 2020). This may be associated with the early onset of centralised measures that have been accompanied by daily news reports on new cases in the country and abroad by the Ministry of Health. In addition to this, there has been widespread information about the disease's nature and facts in the media and on social networking platforms. The significant positive association between levels of education and COVID-19 knowledge scores supports this speculation. The South Koreans discussed the "infodemic", which had been a tremendous and ongoing challenge during the COVID-19 pandemic in their study. In agreement with their results, we found a high prevalence of misunderstanding of the source of infection from eating or contacting wild animals (Lee et al., 2021). This also means that policymakers and health professionals should recognise target populations for COVID-19 prevention and health education programs and prioritise providing information to certain demographic groups, particularly the youth and those with a low level of education. Furthermore, children and young adults did not wear a mask when going out. This is contrary to previous studies that reported older age affects risk-taking behaviours (Cobey et al., 2013).

Similar to previous KAP studies, these findings suggest that higher COVID-19 knowledge scores were found to be significantly associated with a higher likelihood of positive attitudes and appropriate practices toward the COVID-19 pandemic, indicating the importance of improving knowledge to raise attitudes and appropriate practices toward COVID-19 (Zhong et al., 2020). Despite the higher knowledge score, residents of Ulaanbaatar showed less optimistic attitudes and less appropriate practice compared to the residents of other places than Ulaanbaatar.

Overall, most participants adhered to centralised measures to prevent infection, such as avoiding crowded places and wearing masks when going outside. This optimistic attitude of the Mongolian population could be related to the relatively long absence of local infections of the pandemic. However, $17.6 \%$ of the participants visited a crowded place, and $6.9 \%$ did not wear a mask when going out, representing a high risk of infection with the severe acute respiratory syndrome coronavirus 2 (SARS-CoV2). These risky behaviours were related to age, gender, and marital status that resemble 
the results of the Vietnamese KAP survey (Van Nhu et

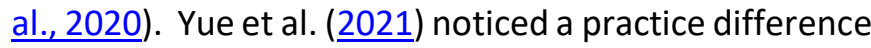
between residing sites of the participant. Similarly, we found that never-married, employed middle-aged women residing in Ulaanbaatar had better practices than others. It may indicate that those people might be the employees who have to work during the period, such as medical professionals and financial services workers. Second, the less adherence to preventive measures could be related to prolonged lockdown and curfew of the city. Compared to Chinese residents of whom $70.1-88.9 \%$ were adherent with the measures during the SARS epidemic, and 96.4-98.0\% were during the COVID-19 pandemic, the adherence rates of the current study were relatively low, which indicate an urgent need to educate the target populations (Bener \& Al-Khal, 2004). In accordance with the findings of the current results, most of the infections spread locally were registered in Ulaanbaatar since the pandemic surged in the society in November. Our results showed an inappropriate reaction of adolescents to wearing a mask when leaving home by comparison with other age groups. The main positive practice of adolescents in this study was maintaining adequate social distancing. It was in accordance with a report from a Jordanian study (Dardas et al., 2020). Therefore, the most vulnerable populations of Mongolian society during the COVID-19 pandemic are young and urban populations with less education, who are more likely to have poor knowledge, negative attitudes, and inappropriate preventive practices toward COVID-19. It is essential to increase the adherence to control measures since poor knowledge and attitudes toward infectious diseases are the risk factors to complications of outbreak management of the outbreak to prevent the infection.

The limitation of this study was the small size of the sample population that was predominantly consisted of women compared to other national populations. This may have been associated with the paper administration we used for the study due to limited access to the internet and the utilisation of online health care information among the rural population. Another limitation of the study is the direct adoption of assessment for attitudes and practices toward COVID19 from an external source without developing a standard questionnaire by in-depth interview, group discussion, and test-retest validation. Due to the limitations and the local outbreak of the infection since

November, more studies are required to investigate the KAP toward COVID-19 among the general population in Mongolia to facilitate the battle against the disease. It is essential to evaluate mental distress in the general population during this pandemic; thus, having good knowledge, a positive attitude, and practice toward COVID-19 is a preventive measure for mental distress (Rias et al., 2020).

\subsection{CONCLUSIONS}

In summary, our findings suggest that the Mongolian population of well-educated, employed, older people with a relatively high income had good knowledge, optimistic attitudes, and appropriate practices towards COVID-19 during the initial period of the COVID-19 pandemic. In addition, good knowledge is associated with optimistic attitudes and appropriate practices towards COVID-19, suggesting that health education programs should be aimed at improving COVID-19 knowledge essential to public adherence to centralised measures among young and urban populations.

\begin{abstract}
Acknowledgements: The authors acknowledge the assistance of the MonTimeline cohort study team of the Brain Science Institute at the Mongolian National University of Medical Sciences. We greatly appreciate those who participated in our study and 64 cluster centre coordinators who supported collecting data.
\end{abstract}

Author Contributions: E.T., B.L., and T.J. conceived and designed the study; E.T., T.A., O.D., M.E., M.D. and G.T., performed and collected the data; E.B., G.T., and B.L analysed the data; M.D., D.B., and T.J. contributed reagents and materials; E.T., E.B., and B.L. wrote the paper; O.T., D.B., and T.J. edited and reviewed the paper.

Conflicts of Interest: The authors declare no conflict of interest.

\section{References}

Azlan, A. A., Hamzah, M. R., Sern, T. J., Ayub, S. H., \& Mohamad, E. (2020). Public knowledge, attitudes and practices towards COVID-19: A cross-sectional study in Malaysia. PLoS One, 15(5), e0233668. https://doi.org/10.1371/journal.pone.0233668

Bener, A., \& Al-Khal, A. (2004). Knowledge, attitude and practice towards SARS. Journal of The Royal Society for the Promotion of Health, 124(4), 167-170. https://doi.org/10.1177/146642400412400408

Cobey, K. D., Stulp, G., Laan, F., Buunk, A. P., \& Pollet, T. V. (2013). Sex differences in risk taking behavior among dutch cyclists. Evolutionary Psychology, 11(2), 350-364. https://doi.org/10.1177/147470491301100206 
Dardas, L. A., Khalaf, I., Nabolsi, M., Nassar, O., \& Halasa, S. (2020). Developing an Understanding of Adolescents' Knowledge, Attitudes, and Practices Toward COVID-19. The Journal of School Nursing, 36(6), 430-441. https://doi.org/10.1177/1059840520957069

Erkhembayar, R., Dickinson, E., Badarch, D., Narula, I., Warburton, D., Thomas, G. N., Ochir, C., \& Manaseki-Holland, S. (2020). Early policy actions and emergency response to the COVID-19 pandemic in Mongolia: experiences and challenges. The Lancet Global Health, 8(9), e1234-e1241. https://doi.org/10.1016/S2214-109X(20)30295-3

Ferdous, M. Z., Islam, M. S., Sikder, M. T., Mosaddek, A. S. M., Zegarra-Valdivia, J. A., \& Gozal, D. (2020). Knowledge, attitude, and practice regarding COVID-19 outbreak in Bangladesh: An onlinebased cross-sectional study. PLOS ONE, 15(10 October), 1-17. https://doi.org/10.1371/journal.pone.0239254

Lee, M., Kang, B. A., \& You, M. (2021). Knowledge, attitudes, and practices (KAP) toward COVID-19: a cross-sectional study in South Korea. BMC Public Health, 21(1), 295. https://doi.org/10.1186/s12889-021-10285-y

Ministry of Health Mongolia. (2020). Covid-19 report. https://covid19.mohs.mn/p/2020-оны-10-дугаар-сарын-18-өдрийннөхцөл-байдлын-мэдээ/927/

Munster, V. J., Koopmans, M., van Doremalen, N., van Riel, D., \& de Wit, E. (2020). A Novel Coronavirus Emerging in China Key Questions for Impact Assessment. New England Journal of Medicine, 382(8), 692-694. https://doi.org/10.1056/nejmp2000929

Ngwewondo, A., Nkengazong, L., Ambe, L. A., Ebogo, J. T., Mba, F. M., Goni, H. O., Nyunaï, N., Ngonde, M. C., \& Oyono, J. L. E. (2020). Knowledge, attitudes, practices of/towards COVID 19 preventive measures and symptoms: A cross-sectional study during the exponential rise of the outbreak in Cameroon. PLoS Neglected Tropical Diseases, 14(9), 1-15. https://doi.org/10.1371/journal.pntd.0008700

Qutob, N., \& Awartani, F. (2021). Knowledge, attitudes and practices (KAP) towards COVID-19 among Palestinians during the COVID-19 outbreak: A cross-sectional survey. PLOS ONE, 16(1 January), 1-11. https://doi.org/10.1371/journal.pone.0244925

Rias, Y. A., Rosyad, Y. S., Chipojola, R., Wiratama, B. S., Safitri, C. I., Weng, S. F., . . Tsai, H. T. (2020). Effects of Spirituality, Knowledge, Attitudes, and Practices toward Anxiety Regarding COVID-19 among the General Population in INDONESIA: A Cross-Sectional Study. Journal of Clinical Medicine, 9(12). https://doi.org/10.3390/jcm9123798

Taber, K. S. (2018). The Use of Cronbach's Alpha When Developing and Reporting Research Instruments in Science Education. Research in Science Education, 48(6), 1273-1296. https://doi.org/10.1007/s11165-016-9602-2

Tachfouti, N., Slama, K., Berraho, M., \& Nejjari, C. (2012). The impact of knowledge and attitudes on adherence to tuberculosis treatment: A case-control study in a moroccan region. Pan African Medical Journal, 12(1), 1-8. https://doi.org/10.11604/pamj.2012.12.52.1374

Van Nhu, H., Tuyet-Hanh, T. T., Van, N. T. A., Linh, T. N. Q., \& Tien, T. Q. (2020). Knowledge, Attitudes, and Practices of the Vietnamese as Key Factors in Controlling COVID-19. Journal of Community Health, 45(6), 1263-1269. https://doi.org/10.1007/s10900-020-00919-4

WHO. (2020a). Coronavirus disease (COVID-19) Weekly Epidemiological Update and Weekly Operational Update. https://covid19.who.int

WHO. (2020b). Statement on the second meeting of the International Health Regulations (2005) Emergency Committee regarding the outbreak of novel coronavirus (2019-nCoV). 2019-NCoV outbreak Is an Emergency of International Concern] Switzerland. https://www.who.int/news/item/30-01-2020-statement-on-the-second-meeting-of-theinternational-health-regulations-(2005)-emergency-committee-regarding-the-outbreak-of-novel-coronavirus-(2019ncov)

Woods, S. P., Fazeli, P. L., Matchanova, A., Vance, D. E., Medina, L. D., \& Morgan, E. E. (2020). Dementia knowledge is low in adults with HIV disease. International Psychogeriatrics, 32(3), 415-416. https://doi.org/10.1017/S104161021900139X

Yue, S., Zhang, J., Cao, M., \& Chen, B. (2021). Knowledge, Attitudes and Practices of COVID-19 Among Urban and Rural Residents in China: A Cross-sectional Study. Journal of Community Health, 46(2), 286-291. https://doi.org/10.1007/s10900-020-00877-x

Zhong, B. L., Luo, W., Li, H. M., Zhang, Q. Q., Liu, X. G., Li, W. T., \& Li, Y. (2020). Knowledge, attitudes, and practices towards COVID-19 among chinese residents during the rapid rise period of the COVID-19 outbreak: A quick online cross-sectional survey. International Journal of Biological Sciences, 16(10), 1745-1752. https://doi.org/10.7150/ijbs.45221 